\title{
DESAIN BANGUNAN PANTAI SEAWALL TERHADAP TINGGI GELOMBANG (STUDI KASUS PANTAI PADANG)
}

\author{
Muhammad Noer Syahputra ${ }^{1)}$, Besperi ${ }^{1)}$, Muhammad Fauzi ${ }^{1)}$ \\ ${ }^{1)}$ Program Studi Teknik Sipil, Fakultas Teknik UNIB \\ Jl. W.R. Supratman Kandang Limun, Kota Bengkulu 38371 \\ Corresponding author : muhammadnoersyahputra@gmail.com
}

\begin{abstract}
Abstrak
Pantai Padang merupakan salah satu pantai di Sumatera yang mengalami abrasi. Abrasi menyebabkan kerusakan fasilitas umum dikawasan tersebut, Tujuan penelitian ini adalah untuk mendesain bangunan pantai seawall di Pantai Kota Padang. Metode pelaksanaan penelitian yang digunakan dengan pengolahan data primer yaitu survei langsung di lapangan (Hs dan Ts) sedangkan data sekunder menggunakan metode analisis data angin, dan analisis data pasang surut. Data sekunder pada penelitian ini adalah data angin yang diambil selama 10 tahun (20102019) yang diperoleh dari Badan Meteorologi Klimatologi dan Geofisika (BMKG) Maritim Teluk Bayur dan data pasang surut diambil selama 5 tahun terakhir (2015-2019) yang diperoleh dari PT. Pelabuhan Indonesia II Teluk Bayur. Hasil dari perhitungan penelitian seawall mempunyai panjang 22,58 m, elevasi mercu 5,31 m, dan elevasi bangunan 9,31 m, lebar puncak $4 \mathrm{~m}$. Berat unit lapis pelindung seawall $\mathrm{W}=4,152 \mathrm{ton}, \mathrm{W} / 10=415,2 \mathrm{~kg}, \mathrm{~W} / 200=21 \mathrm{~kg}$, dan jumlah lapis pelindung tiap $10 \mathrm{~m}^{2}$ sebanyak 11 buah.
\end{abstract}

Kata kunci :Bangunan Pengaman Pantai, Seawall.

\section{Abstract}

Padang Beach is one of the beaches in Sumatra that have an abrasion. Abrasion causes damage to public facilities in the region, the purpose of this research is to design a seawall beach building in the city of Padang Beach. The implementation method of research used with primary data processing is a direct field survey ( $H s$ and $T s$ ) while secondary data using wind data analysis methods, and the analysis of tidal data. Secondary data on this research is the wind data taken for 10 years (2010-2019) obtained from the Meteorological and Geophysical Agency of Meteorology (BMKG) and tidal data taken over the last 5 years (2015-2019) obtained from PT. Pelabuhan Indonesia II of Teluk Bayur. The outcome of the seawall research calculation has a length of $22.58 \mathrm{~m}$, landmark elevation $5.31 \mathrm{~m}$, and the building elevation of $9.31 \mathrm{~m}$, the peak width of $4 \mathrm{~m}$. Weight of seawall protective unit $W=4.152 \mathrm{tons}, W / 10=415.2 \mathrm{~kg}, W / 200=$ $21 \mathrm{~kg}$, and the protective sum of each $10 \mathrm{~m} 2$ as much as 11 pieces.

Keywords :Beach building, seawall. 


\section{PENDAHULUAN}

Kota Padang merupakan salah satu kawasan andalan dalam pembangunan di Sumatera Barat memiliki penduduk lebih dari 830.000 jiwa dan kawasan pantai kritis sepanjang $18 \mathrm{~km}$ dari Batang arau sampai dengan Batang anai. Sebagai ibukota propinsi pertumbuhan daerah pemukiman sangat pesat dan tidak merata yang ditandai lebih dari $70 \%$ warganya mendiami kawasan aliran sungai dan pantai.Seiring dengan perkembangan dan pertumbuhan ekonomi menimbulkan peningkatan kebutuhan lahan pantai serta berbagai sarana dan prasarana yang akan menyebabkan berbagai masalah di daerah pantai, diantaranya sedimentasi, abrasi, pencemaran lingkungan, pemukiman kumuh dan lain-lain.

Garis pantai posisinya bersifat berubahubah dipengaruhi oleh dinamika kelautan, dan erosi yang terjadi (Triatmodjo, 1999).Perubahan garis pantai dipengaruhi oleh dua faktor, diantaranya faktor alam dan faktor manusia.Arus, gelombang, sedimentasi, angin, bentuk muka pantai, dan sungai merupakan beberapa penyebab perubahan garis pantai yang disebabkan oleh faktor alam.

Sedangkan kegiatan pembangunan pelabuhan, fasilitas daerah pantai, pertambangan, kerusakan pantai, pariwisata, dan reklamasi merupakan penyebab perubahan garis pantai yang disebabkan oleh faktor manusia.Abrasi pantai didefinisikan sebagai mundurnya garis pantai dari posisi asalnya (Triatmodjo, 1999). Abrasi yang terjadi pada Pantai Padang menimbulkan berbagai kerusakan contohnya kerusakan pada masjid.

Berdasarkan permasalahan yang ada, maka penulis tertarik untuk melakukan penelitian tentang Seawall.Seawall berfungsi sebagai pelindung pantai terhadap serangan gelombang dan untuk menahan terjadinya limpasan gelombang ke daratan di belakangnya.Sehingga dengan adanya seawall dapat mencegah terjadinya abrasi.

\section{Tujuan Penelitian}

1. Merencanakan bangunan seawall yang sesuai dengan lokasi studi.

2. Mengetahui tinggi gelombang signifikan (Hs) dan menentukan periode gelombang signifikan (Ts) dipantai Padang.

\section{Batasan Masalah}

1. Lokasi penelitian dilakukan di Pantai Padang.

2. Penelitian ini dilakukan hanya untuk mendesain seawall sesuai dengan keadaan gelombang dan pasang surut tanpa meninjau perhitungan detail konstruksi

3. Data pasang surut selama 5 tahun yaitu dari tahun 2015-2019 dan data angin selama 10 tahun yaitu dari tahun 20102019.

4. Pengukuran dan pengamatan langsung di lapangan yaitu pencatatan tinggi gelombang dengan menggunakan alat ukur total station, dan alat untuk pengambilan data di lapangan dianggap sudah valid.

\section{METODE PENELITIAN}

\section{Lokasi Penelitian}

Lokasi penelitian tentang berada di Pantai Padang yang terletak pada koordinat $00^{\circ} 57^{\circ} 50^{\prime \prime} \mathrm{S}$ dan $100^{\circ} 21^{\prime}$ $05 " \mathrm{~T}$

\section{Survei Lapangan}

Studi observasi dilakukan pengamatan secara langsung terhadap struktur bangunan pengaman pantai (seawall) di Pantai Padang. 


\section{Metode Pengumpulan Data}

Pengumpulan data yang dilakukan dalam menganalisis struktur bangunan pengaman pantai (seawall) dilakukan secara primer yaitu pengamatan secara langsung dan secara sekunder yang berupa data angin, data pasang surut dan data topografi yang didapat dari instansi terkait.

\section{Data Primer}

Adapun data primer pada penelitian adalah data tinggi gelombang yang diperoleh dari hasil pengukuran tinggi gelombang secara langsung dilapangan.Pengambilan data tinggi gelombang dilakukan pada saat pasang surut purnama. Waktu pengambilan data tinggi gelombang tersebut dapat ditentukan berdasarkan data pasang surut PT PELINDO II Teluk Bayur,

\section{Data sekunder}

Data Sekunder pada penelitian ini adalah data angin yang di dapat dari Badan Meteorologi Klimatologi dan Geofisika (BMKG) maritime teluk bayur.Dalam penelitian ini digunakan data angin maksimum dan arah angin terbanyak dengan data 10 tahun terakhir yaitu dari tahun 2010-2019 serta data pasang surut selama 5 tahun terakhir yaitu dari tahun 2015-2019.

\section{Metode Pengolahan Data}

Metode pengolahan data pada penelitian ini adalah dengan mengolah data yang ada yaitu data primer dan data sekunder dengan menggunakan rumus yang ada.

\section{Pengolahan data primer}

a. Data hasil survei tinggi gelombang disusun berdasarkan waktu pencatatan.

b. Menentukan tinggi gelombang 33\%.

c. Mengurutkan data dari yang terbesar hingga yang terkecil.

d. Menghitung rata-rata data terbesar untuk mendapatkan nilai Hs (tinggi gelombang signifikan) dan Ts (periode gelombang signifikan).

\section{Pengolahan Data Sekunder}

Analisis data angin

a. Data kecepatan angin 10 tahun terakhir pada tahun 2010-2019, kemudian data tersebut dikelompokkan tiap kecepatan angin dengan rentan 10 misalnya $0-10$, 10-20 dan seterusnya. Dari tabel persentase tersebut dapat digambarkan ke dalam mawar angin dan akan terlihat arah angin yang dominan.

b. Dilakukan perhitungan faktor tegangan angin untuk tiap tahunnya. Dimana nilai $\mathrm{R}_{\mathrm{L}}$ dapat diperoleh dengan menggunakan grafik penentu faktor tegangan angin, kemudian dicari nilai $\mathrm{Uw}=\mathrm{R}_{\mathrm{L}} \mathrm{X} \quad \mathrm{U}_{\mathrm{L}}$ dan $\mathrm{U}_{\mathrm{A}}=0,71 \mathrm{Uw}^{1,23}$.

c. Perhitungan peramalan tinggi gelombang signifikan (Hs) dan periode gelombang signifikan (Ts) dari data BMKG. Perhitungan ini dengan menggunakan data rata-rata nilai $\mathrm{U}_{\mathrm{A}}$ tahun 2010-2019, nilai $\mathrm{g}=9,81$ dan nilai fetch efektif.

\section{Peralatan dan Tenaga Penelitian}

Peralatan, tenaga, dan bahan penelitian yang diperlukan dalam pengambilan data dan pengolahan data adalah:

1. Tenaga bantu dalam survei

2. Total Station

3. Stopwatch

4. Software Autocad digunakan untuk menggambar mawar angin dan gambar bangunan pantai.

\section{HASIL DAN PEMBAHASAN}

\section{Analisis Data Angin}

Angin sangat penting dalam merencanakan bangunan pelindung pantai, karena angin menimbulkan arus dan gelombang. Gelombang yang menyerang bangunan pantai akan menimbulkan gaya-gaya yang bekerja pada bangunan tersebut. Data kecepatan angin setiap bulan dalam 10 tahun (2010-2019) dapat dilihat pada tabel 1 
Tabel 1 Data Kecepatan dan Arah Angin Maksimum (m/det)

\begin{tabular}{|c|c|c|c|c|c|c|c|c|c|c|}
\hline Bulan & 2010 & 2011 & 2012 & 2013 & 2014 & 2015 & 2016 & 2017 & 2018 & 2019 \\
\hline Januari & $\begin{array}{l}5 \\
\text { SW }\end{array}$ & $\begin{array}{l}5 \\
\mathrm{~N}\end{array}$ & $\begin{array}{l}5 \\
\mathrm{NE}\end{array}$ & $\begin{array}{l}7 \\
\mathrm{~N} \\
\end{array}$ & $\begin{array}{l}4 \\
\mathrm{~N}\end{array}$ & $\begin{array}{l}6 \\
\mathrm{~N} \\
\end{array}$ & $\begin{array}{l}5 \\
\mathrm{~W} \\
\end{array}$ & $\begin{array}{l}6 \\
\text { SW }\end{array}$ & $\begin{array}{l}8 \\
\text { NW }\end{array}$ & $\begin{array}{l}5 \\
\text { SW }\end{array}$ \\
\hline Februari & $\begin{array}{l}4 \\
S\end{array}$ & $\begin{array}{l}5 \\
N\end{array}$ & $\begin{array}{l}5 \\
S\end{array}$ & $\begin{array}{l}4 \\
\mathrm{~N}\end{array}$ & $\begin{array}{l}5 \\
N\end{array}$ & $\begin{array}{l}6 \\
N\end{array}$ & $\begin{array}{l}9 \\
\mathrm{NE}\end{array}$ & $\begin{array}{l}5 \\
S\end{array}$ & $\begin{array}{l}6 \\
\mathrm{~N}\end{array}$ & $\begin{array}{l}5 \\
S \\
\end{array}$ \\
\hline Maret & $\begin{array}{l}5 \\
\text { SW }\end{array}$ & $\begin{array}{l}4 \\
\mathrm{~N}\end{array}$ & $\begin{array}{l}18 \\
\mathrm{~N}\end{array}$ & $\begin{array}{l}6 \\
\mathrm{~N}\end{array}$ & $\begin{array}{l}5 \\
\text { SE }\end{array}$ & $\begin{array}{l}5 \\
\mathrm{~N}\end{array}$ & $\begin{array}{l}4 \\
\mathrm{~N} \\
\end{array}$ & $\begin{array}{l}6 \\
\text { SW }\end{array}$ & $\begin{array}{l}7 \\
N\end{array}$ & $\begin{array}{l}10 \\
\mathrm{~N}\end{array}$ \\
\hline April & $\begin{array}{l}5 \\
S \\
\end{array}$ & $\begin{array}{l}4 \\
N\end{array}$ & $\begin{array}{l}6 \\
\mathrm{NE}\end{array}$ & $\begin{array}{l}4 \\
N\end{array}$ & $\begin{array}{l}4 \\
\mathrm{~N}\end{array}$ & $\begin{array}{l}5 \\
\mathrm{~N}\end{array}$ & $\begin{array}{l}8 \\
\mathrm{~N}\end{array}$ & $\begin{array}{l}5 \\
N \\
\end{array}$ & $\begin{array}{l}5 \\
N\end{array}$ & $\begin{array}{l}7 \\
S\end{array}$ \\
\hline $\mathrm{Mei}$ & $\begin{array}{l}4 \\
N\end{array}$ & $\begin{array}{l}5 \\
S\end{array}$ & $\begin{array}{l}8 \\
\mathrm{NE}\end{array}$ & $\begin{array}{l}5 \\
\mathrm{~N}\end{array}$ & $\begin{array}{l}7 \\
\mathrm{~N}\end{array}$ & $\begin{array}{l}10 \\
\mathrm{~N}\end{array}$ & $\begin{array}{l}3 \\
\mathrm{~N}\end{array}$ & $\begin{array}{l}15 \\
\mathrm{~N}\end{array}$ & $\begin{array}{l}4 \\
N\end{array}$ & $\begin{array}{l}4 \\
S\end{array}$ \\
\hline Juni & $\begin{array}{l}5 \\
S\end{array}$ & $\begin{array}{l}5 \\
\mathrm{~N}\end{array}$ & $\begin{array}{l}6 \\
N\end{array}$ & $\begin{array}{l}4 \\
\mathrm{NE}\end{array}$ & $\begin{array}{l}8 \\
\mathrm{~N}\end{array}$ & $\begin{array}{l}11 \\
\text { SW }\end{array}$ & $\begin{array}{l}15 \\
S\end{array}$ & $\begin{array}{l}5 \\
\mathrm{~N}\end{array}$ & $\begin{array}{l}6 \\
\mathrm{~N}\end{array}$ & $\begin{array}{l}5 \\
S\end{array}$ \\
\hline Juli & $\begin{array}{l}5 \\
\mathrm{NE}\end{array}$ & $\begin{array}{l}5 \\
S\end{array}$ & $\begin{array}{l}5 \\
\text { SW }\end{array}$ & $\begin{array}{l}5 \\
N \\
\end{array}$ & $\begin{array}{l}8 \\
S\end{array}$ & $\begin{array}{l}6 \\
S\end{array}$ & $\begin{array}{l}5 \\
\mathrm{~N}\end{array}$ & $\begin{array}{l}5 \\
\mathrm{~N}\end{array}$ & $\begin{array}{l}7 \\
N\end{array}$ & $\begin{array}{l}5 \\
\text { S }\end{array}$ \\
\hline Agustus & $\begin{array}{l}5 \\
N\end{array}$ & $\begin{array}{l}7 \\
N\end{array}$ & $\begin{array}{l}4 \\
S\end{array}$ & $\begin{array}{l}4 \\
\mathrm{~N}\end{array}$ & $\begin{array}{l}5 \\
\text { SW }\end{array}$ & $\begin{array}{l}6 \\
\mathrm{~N}\end{array}$ & $\begin{array}{l}10 \\
E\end{array}$ & $\begin{array}{l}5 \\
\mathrm{~N}\end{array}$ & $\begin{array}{l}5 \\
N\end{array}$ & $\begin{array}{l}5 \\
S\end{array}$ \\
\hline September & $\begin{array}{l}4 \\
\text { SW }\end{array}$ & $\begin{array}{l}4 \\
N\end{array}$ & $\begin{array}{l}5 \\
S\end{array}$ & $\begin{array}{l}5 \\
\mathrm{~N}\end{array}$ & $\begin{array}{l}5 \\
S\end{array}$ & $\begin{array}{l}5 \\
\mathrm{~N}\end{array}$ & $\begin{array}{l}9 \\
\mathrm{E}\end{array}$ & $\begin{array}{l}4 \\
\mathrm{~N}\end{array}$ & $\begin{array}{l}5 \\
N\end{array}$ & $\begin{array}{l}4 \\
S\end{array}$ \\
\hline Oktober & $\begin{array}{l}8 \\
N\end{array}$ & $\begin{array}{l}5 \\
\text { SW }\end{array}$ & $\begin{array}{l}5 \\
N\end{array}$ & $\begin{array}{l}4 \\
\mathrm{~N}\end{array}$ & $\begin{array}{l}8 \\
N\end{array}$ & $\begin{array}{l}5 \\
\mathrm{~N}\end{array}$ & $\begin{array}{l}3 \\
S\end{array}$ & $\begin{array}{l}5 \\
\mathrm{~N}\end{array}$ & $\begin{array}{l}5 \\
N\end{array}$ & $\begin{array}{l}4 \\
S\end{array}$ \\
\hline November & $\begin{array}{l}5 \\
\mathrm{~N}\end{array}$ & $\begin{array}{l}4 \\
\mathrm{~N}\end{array}$ & $\begin{array}{l}18 \\
\mathrm{~N}\end{array}$ & $\begin{array}{l}5 \\
\mathrm{~N}\end{array}$ & $\begin{array}{l}6 \\
\text { SW }\end{array}$ & $\begin{array}{l}5 \\
\mathrm{~N}\end{array}$ & $\begin{array}{l}8 \\
\mathrm{E}\end{array}$ & $\begin{array}{l}11 \\
\mathrm{~W}\end{array}$ & $\begin{array}{l}4 \\
\mathrm{~N}\end{array}$ & - \\
\hline Desember & $\begin{array}{l}8 \\
\mathrm{~N}\end{array}$ & $\begin{array}{l}8 \\
\mathrm{~N}\end{array}$ & $\begin{array}{l}7 \\
\mathrm{~N}\end{array}$ & $\begin{array}{l}4 \\
\mathrm{~N}\end{array}$ & $\begin{array}{l}5 \\
S \\
\end{array}$ & $\begin{array}{l}8 \\
S\end{array}$ & $\begin{array}{l}4 \\
\mathrm{~N}\end{array}$ & $\begin{array}{l}6 \\
N\end{array}$ & $\begin{array}{l}5 \\
\mathrm{~N}\end{array}$ & - \\
\hline
\end{tabular}

Penentuan persentase angin tiap arah

DataAngin dari BMKG Teluk Bayur dapatdiolahuntuk mengetahui persentase angin tiap arah dengan cara perhitungan pada Tabel 2.

Tabel 2 Jumlah Arah Angin Per Kecepatan $1 \mathrm{~m} / \mathrm{det}$

\begin{tabular}{|c|c|c|c|c|c|c|c|c|}
\hline \multirow{2}{*}{$\begin{array}{l}\text { Kecepatan } \\
(\mathrm{m} / \mathrm{det})\end{array}$} & \multicolumn{8}{|c|}{ Jumlah Arah Angin } \\
\hline & $\mathbf{N}$ & NE & $\bar{E}$ & $\overline{\mathbf{S E}}$ & $\mathbf{S}$ & SW & W & NW \\
\hline $0-1$ & 125 & 80 & 1 & 10 & 208 & 20 & 16 & 5 \\
\hline $1-2$ & 466 & 102 & 13 & 24 & 255 & 82 & 46 & 11 \\
\hline $2-3$ & 1207 & 114 & 31 & 55 & 397 & 243 & 85 & 22 \\
\hline $3-4$ & 1223 & 97 & 33 & 48 & 516 & 227 & 60 & 23 \\
\hline $4-5$ & 506 & 49 & 20 & 12 & 212 & 62 & 19 & 10 \\
\hline$>5$ & 130 & 24 & 9 & 4 & 38 & 19 & 11 & 4 \\
\hline Jumlah & 3657 & 466 & 107 & 153 & 1626 & 653 & 237 & 75 \\
\hline Total & \multicolumn{8}{|l|}{6974} \\
\hline
\end{tabular}

Sumber :Hasil Perhitungan Sendiri, 2019

\section{Pengelompokan data angin :}

Jumlah seluruh data angin $=6974$ data

a. $\quad$ arah South $=208$ data $(0-1 \mathrm{~m} / \mathrm{det})$

b. $\quad$ arah North $=466$ data $(1-2 \mathrm{~m} / \mathrm{det})$

c. arah North West $=22$ data $(2-3 \mathrm{~m} / \mathrm{det})$

Perhitungan persentase angin :

a. $\operatorname{arah}$ South $(\mathrm{N})=2,983 \%$
Untuk arahNorth $(\mathrm{N})=6,682 \%$

Untuk arahNorth West (NW) $=0,315 \%$

Perhitungan ini dilakukan untuk mendapatkan persentase arah angin 10 tahun terakhir dari tahun 2010-2019.Hasil pengolahan data persentase kejadian angin dapat dilihat pada Tabel 3. 
Desain Bangunan Pantai Seawall terhadap Tinggi Gelombang (Studi Kasus Pantai Padang)

Tabel 3 Data Persentase Kejadian Angin

\begin{tabular}{|l||l|l|l|l|l|l|l|l||}
\hline \multirow{2}{*}{$\begin{array}{l}\text { Kecepatan } \\
(\mathbf{m} / \text { det })\end{array}$} & Arah Angin (\%) & NE & E & SE & S & SW & W & NW \\
\hline \hline $0-1$ & 1,792 & 1,147 & 0,014 & 0,143 & 2,983 & 0,287 & 0,229 & 0,072 \\
\hline \hline $1-2$ & 6,682 & 1,463 & 0,186 & 0,344 & 3,656 & 1,176 & 0,660 & 0,158 \\
\hline \hline $2-3$ & 17,307 & 1,635 & 0,445 & 0,789 & 5,693 & 3,484 & 1,219 & 0,315 \\
\hline \hline $3-4$ & 17,537 & 1,391 & 0,473 & 0,688 & 7,399 & 3,255 & 0,860 & 0,330 \\
\hline $4-5$ & 7,256 & 0,703 & 0,287 & 0,172 & 3,040 & 0,889 & 0,272 & 0,143 \\
\hline$>5$ & 1,864 & 0,344 & 0,129 & 0,057 & 0,545 & 0,272 & 0,158 & 0,057 \\
\hline \hline Jumlah & 52,438 & 6,682 & 1,534 & 2,194 & 23,315 & 9,363 & 3,398 & 1,075 \\
\hline \hline Total & $\mathbf{1 0 0 \%}$ & & & & & & & \\
\hline
\end{tabular}

Sumber :Hasil Perhitungan Sendiri, 2019

Penentuan arah angin dominan dengan diagram mawar angin

Mawar angin adalah diagram yang menyederhanakan angin pada sebuah lokasi dengan periode tertentu. sepertiyangterlihatpadaGambar1.

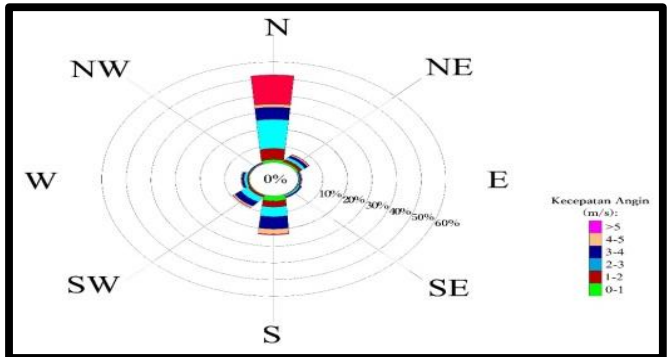

Sumber: Hasil Olahan Sendiri, 2019

Gambar 1 Diagram Mawar Angin (Wind Rose)

\section{Konversi kecepatan angin}

Konversi kecepatan angin dilakukan untuk mencari peramalan tinggi gelombang signifikan (Hs) dan periode gelombang (Ts).Data angin digunakan untuk menentukan arah gelombang dan tinggi gelombang secara empiris.

penentuan nilai tegangan angin kemudian tarik garis horizontal kearah $\mathrm{R}_{\mathrm{L}}$ seperti pada Gambar 2.

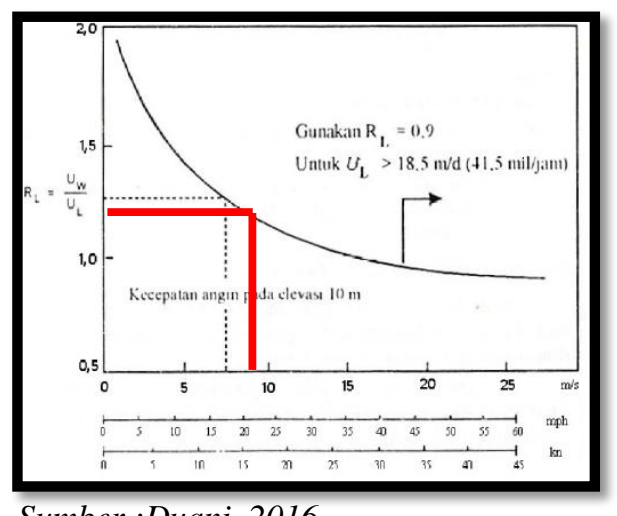

Sumber :Duani, 2016

Gambar 2 Faktor Tegangan Angin

Dari hasil perhitungan $\mathrm{U}_{\mathrm{L}}$ yang diperoleh sebesar $8 \mathrm{~m} /$ det, dengan Gambar 4.2 didapatkan $\mathrm{R}_{\mathrm{L}}$ sebesar :

$$
\begin{aligned}
\mathrm{R}_{\mathrm{L}} & =\frac{U w}{U L} \\
& =1,23
\end{aligned}
$$

Kemudian kecepatan angin di laut (Uw) dapat dihitung dengan menggunakan rumus:

$$
\begin{aligned}
\mathrm{UW} & =\mathrm{R}_{\mathrm{L}} \times \mathrm{U}_{\mathrm{L}} \\
& =1,23 \times 8 \\
& =9,84 \mathrm{~m} / \mathrm{det}
\end{aligned}
$$

Hasil perhitungan $\mathrm{U}_{\mathrm{W}}$, digunakan untuk menentukan faktor tegangan angin $\left(\mathrm{U}_{\mathrm{A}}\right)$ menggunakan rumus :

$$
\begin{aligned}
\mathrm{U}_{\mathrm{A}} & =0,71 \mathrm{Uw}^{1,23} \\
& =0,71 \times 9,84^{1,23} \\
& =11,82 \mathrm{~m} / \mathrm{det}
\end{aligned}
$$


Tabel 4 Perhitungan Faktor Tegangan Angin 2010

\begin{tabular}{|l||l|l||l||l||}
\hline Bulan & $\begin{array}{l}\text { Kecepatan Angin } \\
\left(\mathrm{U}_{\mathrm{L}}\right) \text { Max } \\
(\mathrm{m} / \mathrm{det})\end{array}$ & $\mathrm{R}_{\mathrm{L}}$ & $\begin{array}{l}\mathrm{U}_{\mathrm{W}} \\
(\mathrm{m} / \mathrm{det})\end{array}$ & $\begin{array}{l}\mathrm{U}_{\mathrm{A}} \\
(\mathrm{m} / \mathrm{det})\end{array}$ \\
\hline \hline Januari & 5 & 1,47 & 7,35 & 8,26 \\
\hline \hline Februari & 4 & 1,5 & 6 & 6,43 \\
\hline \hline Maret & 5 & 1,47 & 7,35 & 8,26 \\
\hline \hline April & 5 & 1,47 & 7,35 & 8,26 \\
\hline Mei & 4 & 1,5 & 6 & 6,43 \\
\hline \hline Juni & 5 & 1,47 & 7,35 & 8,26 \\
\hline \hline Juli & 5 & 1,47 & 7,35 & 8,26 \\
\hline \hline Agustus & 5 & 1,47 & 7,35 & 8,26 \\
\hline \hline September & 4 & 1,5 & 6 & 6,43 \\
\hline \hline Oktober & 8 & 1,23 & 9,84 & 11,82 \\
\hline November & 5 & 1,47 & 7,35 & 8,26 \\
\hline \hline Desember & 8 & 1,23 & 9,84 & 11,82 \\
\hline \hline Rata-Rata & $\mathbf{5 , 2 5}$ & $\mathbf{1 , 4 4}$ & $\mathbf{8 , 4 0}$ \\
\hline
\end{tabular}

Sumber : Hasil Perhitungan Olahan Sendiri, 2019

\section{Penentuan fetch efektif}

Fetch adalah jarak perjalanan tempuh pembentukan gelombang dari awal pembangkitannya yang dibatasi oleh bentuk daratan yang mengelilingi laut dan memiliki kecepatan angin yang relatif konstan (Widhianto dkk, 2014).Daerah fetch adalah daerah dengan kecepatan angin konstan. Sedangkan jarak fetch merupakan jarak tanpa rintangan dimana angin sedang bertiup.

Fetch efektif digunakan pada peramalan gelombang untuk mengetahui tinggi dan periode gelombang signifikan.

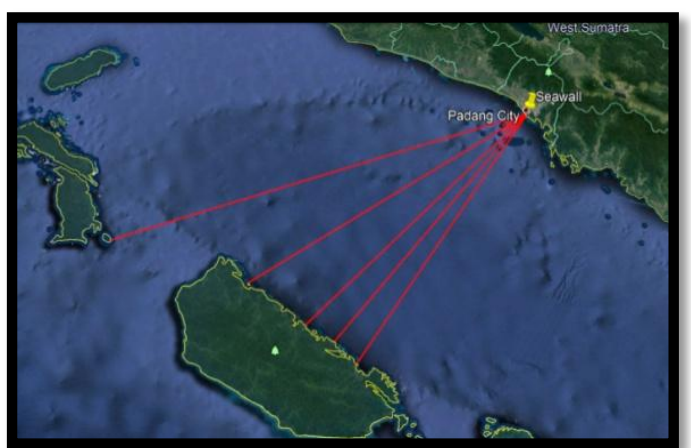

Sumber: Hasil Perhitungan Olahan Sendiri, 2019

Gambar 3. Gambar Fetch

\section{Perhitungan Pasang Surut}

Secara umum pasang surut diberbagai daerah dapat dibedakan dalam empat tipe, yaitu pasang surut harian tunggal (diurnal tide), harian ganda (semidiurnal tide) dan dua jenis campuran (Triatmodjo, 2012).Data pasang surut digunakan tertinggi dari data 5 tahun $(2015,2016$, 2017, 2018 dan 2019) yaitu : muka air tinggi (high water level)

$$
=1,4 \text { meter }
$$

Muka air rendah (low water level)

$$
=0,1 \text { meter }
$$

Muka air rata-rata (mean water level)

$$
=0,7 \text { meter }
$$

Penelitian ini bertujuan untuk mendesain bangunan seawall pada kedalaman yang berkisar 4 meter di bawah permukaan laut, sehingga nilai kedalaman air di lokasi, yaitu:

$\mathrm{d}_{\text {HWL }}=1,4-(-4) \quad=5,4$ meter

$\mathrm{d}_{\mathrm{LWL}}=0,1-(-4) \quad=4,1$ meter

$\mathrm{d}_{\text {MWL }}=0,7-(-4) \quad=4,7$ meter

Sehingga untuk perhitungan selanjutnya, nilai $\mathrm{d}_{\mathrm{HWL}}$ dianggap sebagai kedalaman air (d) dengan nilai $=5,4 \mathrm{~m}$.

\section{Perhitungan Refraksi Gelombang}

Gelombang merupakan faktor utama di dalam penentuan tata letak (layout) pelabuhan, alur pelayaran, perencanaan bangunan pantai dan sebagainya. 
Gelombang di laut dapat dibedakan menjadi beberapa macam yang tergantung pada gaya pembangkitnya (Asnawi, 2012). Nilai periode gelombang adalah nilai periode terbesar dari tahun 2010-2019, yaitu 6,9detik.

$$
\begin{aligned}
& L_{0}=\frac{g T^{2}}{2 \pi} \\
& L_{0}=\frac{9,81 \times 6,9^{2}}{2 \pi}
\end{aligned}
$$

$L_{0}=74,334$ meter

Maka, panjang gelombang yang terjadi di laut sebesar $74,334 \mathrm{~m}$. Kemudian dapat dihitung nilai cepat rambat gelombang di laut dalam $\left(\mathrm{C}_{0}\right)$

$$
\begin{aligned}
C_{0} & =\frac{L_{0}}{T_{S}} \\
C_{0} & =\frac{74,334}{6,9} \\
C_{0} & =10,773 \mathrm{~m} / \mathrm{s}
\end{aligned}
$$

Selanjutnya menghitung nilai $\frac{d}{L_{0}}$, dengan nilai $\mathrm{d}=5,4$ meter.

$\frac{d}{L_{0}}=\frac{5,4}{74,334}=0,073$

nilai $\frac{d}{L}=0,11675$ dengan nilai $\mathrm{Ks}=0,966$ dan $\mathrm{n}=0,8573$.

$$
\begin{aligned}
\frac{d}{L} & =0,11675 \\
L & =\frac{5,4}{0,11675} \\
\mathrm{~L} & =46,55 \text { meter }
\end{aligned}
$$

Panjang gelombang (L) adalah 46,55 meter, kemudian dapat dihitung nilai cepat rambat gelombang $(\mathrm{C})$ :

$\mathrm{C}=\frac{L}{T}$

$\mathrm{C}=\frac{46,55}{6,9}$

$\mathrm{C}=6,75 \mathrm{~m} / \mathrm{s}$

Cepat rambat gelombang (C) adalah 6,75 $\mathrm{m} /$ det.

$\sin \alpha_{1}=\left(\frac{C}{C_{0}}\right) \sin \alpha_{0}$ dimana $\quad \alpha_{0}$ sudut antara garis puncak gelombang di laut dalam dan garis kontur dasar laut (Lampiran 10).

$\alpha=\left(\frac{6,75}{10,773}\right) \sin 21^{\circ}=0,224=12,94^{\circ}$

Maka didapat koefisien refraksinya, yaitu :

$\mathrm{Kr}=\sqrt{\frac{\cos \alpha_{0}}{\cos \alpha}}$

$\mathrm{Kr}=\sqrt{\frac{\cos 21^{\circ}}{\cos 12,94^{\circ}}}=0,978$

Jadi didapatkan koefisien refraksi sebesar 0,978 .

Perhitungan Tinggi di Laut Dalam Ekivalen $\left(\mathrm{H}^{\prime}{ }_{0}\right)$

Ekivalen tinggi gelombang laut dalam dihitung dengan rumus :

$\mathrm{H}^{\prime}{ }_{0}=\mathrm{Kr} \times \mathrm{H}_{0}$

$\mathrm{H}=2,9 \mathrm{~m}$ (perhitungan sebelumnya)

Koefisien refraksi $(\mathrm{Kr})=0,978$

Maka,

$\mathrm{H}^{\prime}{ }_{0}=0,978 \times 2,9$

$2,836 \mathrm{~m}$

\section{Perhitungan Tinggi Gelombang Pecah}

Bangunan selalu mengalami limpasan pada kondisi gelombang sehari-hari dan puncak bangunan rusak sama sekali dan kehilangan bentuk (Istijono, 2014). Perhitungan gelombang pecah ini digunakan rumus berikut :

$\frac{H_{0}^{\prime}}{g T^{2}}=\frac{2,836}{9,81 \times 6,9^{2}}=0,00607$

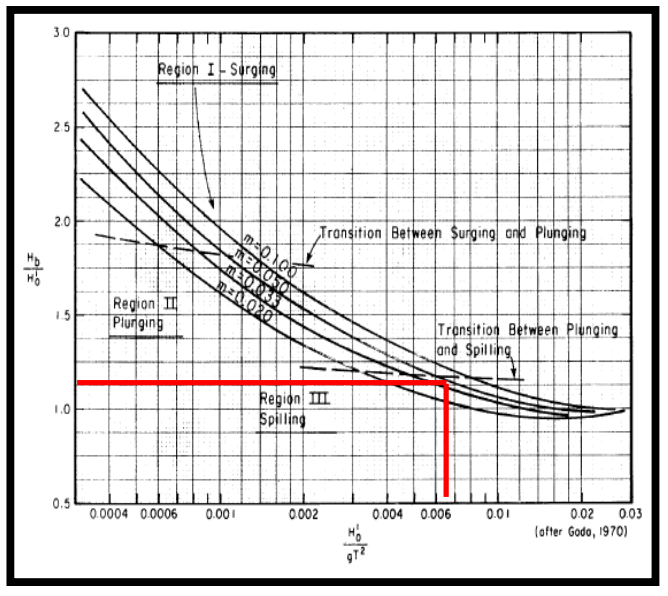

Sumber: Shore Protection Manual, 1984.

Gambar 4. Grafik Tinggi Gelombang Pecah 
Berdasarkan grafik diatas didapatkan nilai $\frac{H_{b}}{H_{0}^{\prime}}=1,18$. Selanjutnya didapat nilai tinggi gelombang pecah perhitungannya sebagai berikut :

$$
\begin{aligned}
& \frac{H_{b}}{H^{\prime}{ }_{o}}=1,18 \\
& \mathrm{H}_{\mathrm{b}}=1,18 \times 2,836 \\
& \mathrm{H}_{\mathrm{b}}=3,34 \mathrm{~m}
\end{aligned}
$$

Setelah diperoleh nilai $\mathrm{H}_{\mathrm{b}}$ selanjutnya mencari nilai $d_{b}$, perhitungannya sebagai berikut:

$\frac{H_{b}}{g T^{2}}=\frac{3,34}{9,81 \times 6,9^{2}}=0,00715$

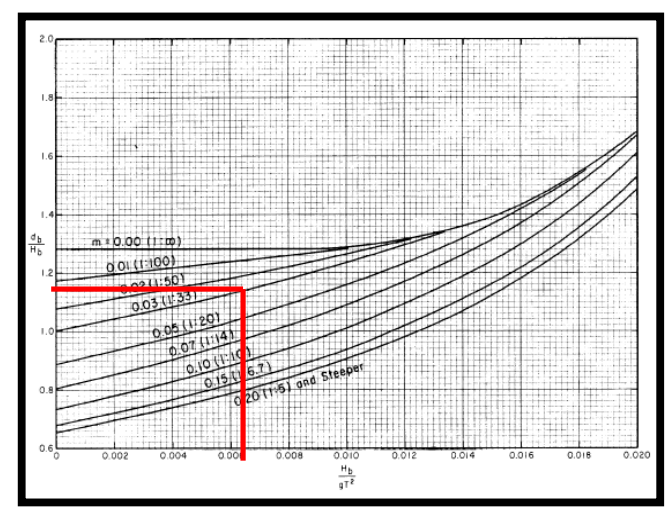

Sumber: Shore Protection Manual, 1984.

Gambar 5. Penentuan Kedalaman Gelombang Pecah

Berdasarkan Gambar 4.6, maka diperoleh nilai $\frac{d_{b}}{H_{b}}=1,19$

$\frac{d b}{H b}=1,19$

$d_{b}=1,19 \times 3,34$

$d_{b}=3,974 \mathrm{~m}$

\section{Perhitungan Elevasi Muka Air}

\section{Rencana}

Elevasi muka air rencana merupakan parameter sangat penting didalam perencanaan bangunan pantai.DWL (Design Water Level) diperlukan karena elevasi air laut yang selalu berubah setiap saat. Rumus untuk menentukan elevasi muka air rencana:

$\mathrm{DWL}=\mathrm{HWL}+\mathrm{SW}+\Delta \mathrm{h}+\mathrm{SLR}$

Dimana,

DWL $=$ Design water level

$\mathrm{HWL}=$ High water level
$\mathrm{Sw}=$ Wave set-up

$\Delta \mathrm{h}=$ Kenaikan elevasi muka air

SLR = Sea level rise (kenaikan muka air laut karena pemanasan global)

Sea level rise (SLR) diperoleh dengan melihat Gambar 6 dimana umur bangunan direncanakan dapat bertahan selama 20 tahun.

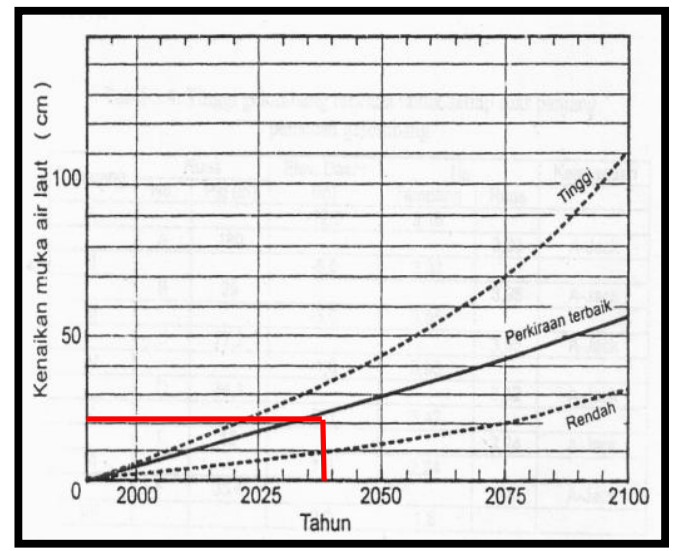

Sumber: Triadmojo, 1999.

Gambar 6. Perkiraan Kenaikan Muka Air Laut Karena Pemanasan Global

Dari grafik diatas, dengan menarik garis vertikal sesuai tahun hingga menyinggung garis perkiraan terbaik, kemudian tarik garis horizontal kekiri didapat nilai SLR yaitu sebesar $20 \mathrm{~cm}=0,22$ meter.

Nilai wind set-up diperoleh dari:

$$
\begin{aligned}
S w & =0,19\left[1-2,82 \sqrt{\frac{H_{b}}{g T^{2}}}\right] H_{b} \\
S= & 0,19\left[1-2,82 \sqrt{\frac{3,34}{9,81 \times 6,9^{2}}}\right] 3,34 \\
& =0,483 \mathrm{~m}
\end{aligned}
$$

Panjang fetch efektif dari arah barat dengan sudut $\left(\alpha=21^{\circ}\right)$ adalah $55 \mathrm{~km}$ dan $\mathrm{U}_{\mathrm{A}}=24,24 \mathrm{~m} / \mathrm{det}$, maka besar wind set up adalah :

$$
\begin{array}{ll}
\mathrm{U} & =0,71 \times \mathrm{U}_{\mathrm{A}}^{1,23} \\
\mathrm{U} & =35,83 \mathrm{~m} / \mathrm{det} \\
\mathrm{Vy} & =\mathrm{U} \sin \alpha \\
\mathrm{Vy} & =35,83 \sin 21^{\circ}=12,84 \mathrm{~m} / \mathrm{s} \\
\mathrm{Fy} & =\mathrm{F} \sin \alpha \\
\mathrm{Fy} & =55 \sin 21^{\circ}=19,710 \mathrm{~km}
\end{array}
$$

Perbandingan kedalaman air dengan panjang gelombang dilaut dalam adalah : 


$$
\begin{aligned}
\frac{d}{L_{0}} & =\frac{5,4}{74,334}=13,76 \\
d & =\frac{1}{13.76} \times 74,334=5,4 \text { meter } \\
\Delta \mathrm{h} & =\mathrm{Fy} \frac{\mathrm{V}^{2}}{2 g d} \\
\Delta \mathrm{h} & =19710 \times\left(3,5 \times 10^{-6}\right) \frac{12,84^{2}}{2 \times 9,81 \times 5,4} \\
\Delta \mathrm{h} & =0,107 \text { meter }
\end{aligned}
$$

Dari data yang diperoleh maka nilai DWL :

$\mathrm{DWL}=\mathrm{HWL}+\mathrm{SW}+\Delta \mathrm{h}+\mathrm{SLR}$

$\mathrm{DWL}=1,4+0,462+0,107+0,22$

$\mathrm{DWL}=2,189 \approx 2,20 \mathrm{~m}$

\section{Penentuan elevasi puncak seawall}

Elevasi puncak bangunan memperhitungkan tinggi jagaan (fb) 0,5 meter, dengan menggunakan persamaan:

$\mathrm{El}_{\text {puncak }}=\mathrm{DWL}+\mathrm{Ru}+0,5$

Tinggi muka air tertinggi $(\mathrm{HWL})=1,4$ meter

Tinggi gelombang Pecah $(\mathrm{H})=2,9$ meter

Periode gelombang $(\mathrm{T})=6,9$ detik

Tinggi gelombang laut dalam $(\mathrm{Lo})=74,334$ $\mathrm{m}$.

Run-up gelombang didefinisikan sebagai level pencapaian tertinggi gelombang laut pada sebuah struktur yang mempunyai permukaan miring, diukur secara vertikal dari muka air diam Still Water Level (SWL) (Duani, 2016).Besar koefisien nilai Run-up didapatkan berdasarkan fungsi bilangan irebaren.

Bilangan Iribaren :

$I r=\frac{\tan \theta}{\left(\frac{H}{L_{o}}\right)^{\frac{1}{2}}}=\frac{1}{\left(\frac{2,9}{74,334}\right)^{\frac{1}{2}}}=5,06 \approx 5$

Dengan menggunakan Gambar 7, dihitung nilai run-up.Untuk lapis lindung dari batu pecah.

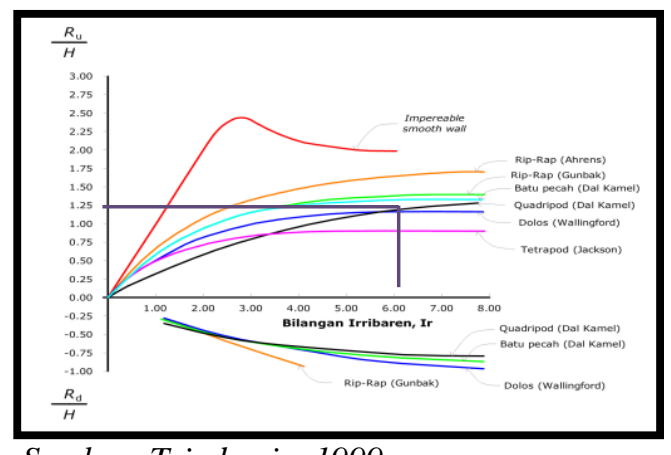

Sumber: Triadmojo, 1999

Gambar 7. Grafik Run-up Gelombang
Dari Gambar 4.8 didapat nilai $\frac{R u}{H}=1,3$

$\mathrm{Ru}=1,3 \times 2,9=3,77 \mathrm{~m}$

Sehingga elevasi puncak seawall dapat dihitung sebagai berikut :

$$
\begin{aligned}
\mathrm{El}_{\text {puncak }} & =\mathrm{DWL}+\mathrm{Ru}+0,5 \\
& =2,20+3,77+0,5 \\
& =5,31 \mathrm{~m} \\
\mathrm{EI}_{\text {bangunan }} & =\text { Elevasi }_{\text {puncak }}-\text { Elevasi }_{\text {dasarlaut }} \\
& =5,31-(-4) \\
& =9,31 \mathrm{~m}
\end{aligned}
$$

Elevasi bangunan seawall yang didapat dari perhitungan diatas 9,31 meter.

$\mathrm{d}_{\mathrm{b}}<\mathrm{d}_{\mathrm{LWL}}<\mathrm{d}_{\mathrm{HWL}}$

$3,517<4,1<5,4$ (gelombang tidak pecah)

4.7.2 Perhitungan berat lapis lindung

Menghitung berat dan tebal lapis lindung dengan menggunakan rumus sebagai berikut :

$$
W=\frac{\gamma_{r} H^{3}}{K_{D}\left(S_{r}-1\right)^{3} \cot \theta}
$$

Keterangan:

$\mathrm{W}=$ Berat butir batu pelindung (ton)

$\gamma_{\mathrm{r}}=$ Berat jenis batu $\left(2,65 \mathrm{t} / \mathrm{m}^{3}\right)$

$\gamma_{\mathrm{a}}=$ Berat satuan air laut $\left(1,03 \mathrm{ton} / \mathrm{m}^{3}\right)$

$\mathrm{H}=$ Tinggi gelombang rencana

$\theta=$ Sudut kemiringan sisi pemecah gelombang $(\theta=2)$

$\mathrm{K}_{\mathrm{D}}=$ Koefisien stabilitas lengan bangunan $\left(\mathrm{K}_{\mathrm{D}}=2\right)$

$B=n \times K_{\Delta}\left[\frac{W}{\gamma_{r}}\right]^{1 / 3}$

Keterangan :

$\mathrm{t}=$ Tebal lapis dinding (meter)

$\mathrm{n}=2$ (minimum)

$\mathrm{K}_{\Delta}=$ Koefisien Lapis pelindung $\left(\mathrm{K}_{\Delta}=1,15\right)$

$\mathrm{W}=$ Berat butir lapis pelindung (ton)

$\left(\gamma_{\mathrm{r}}\right)=$ Berat Jenis Batu lindung (Beton

$$
=2,4 \mathrm{t} / \mathrm{m}^{3} \text { ) }
$$

1. Lapis lindung pertama

Berat lapis lindung :

$\mathrm{W}=\frac{2,65 \times 2,9^{3}}{2 \times\left(\frac{2,65}{1,03}-1\right)^{3} \times 2}=4,152$ ton

Tebal lapis lindung :

$t=2 \times 1,15\left[\frac{4,152}{2,65}\right]^{1 / 3}=2,671$ meter 
2. Lapisan pelindung kedua:

Berat butir :

$\frac{\mathrm{W}}{10}=\frac{4,152}{10}=0,4152$ ton

$$
=415,2 \text { kilogram }
$$

Tebal lapis lindung :

$t=2 \times 1,15\left[\frac{0,4152}{2,65}\right]^{1 / 3}=1,239$ meter

3. Berat batu lapis inti (core) :

$$
\begin{aligned}
\frac{\mathrm{W}}{200}=\frac{4,152}{200} & =0,0207 \text { ton } \\
& =21 \text { kilogram }
\end{aligned}
$$

Perhitungan Lebar Puncak Seawall

Untuk menentukan lebar puncak seawall menggunakan rumus berikut:

$$
B=n \times K_{\Delta}\left[\frac{W}{\gamma_{r}}\right]^{1 / 3}
$$

Dimana :

$$
\begin{aligned}
& \mathrm{B}=\text { Lebar Puncak } \\
& \mathrm{n}=3 \\
& \mathrm{~K}_{\Delta}=\text { Koefisien Lapis beton } \\
& \mathrm{W}=1,15 \text { (lampiran 7) } \\
&\left(\gamma_{\mathrm{r}}\right)=\text { Berat butir lapis pelindung (ton) } \\
&=2,4 \mathrm{t} / \mathrm{m}^{3} \text { ) } \\
& B=n \times K_{\Delta}\left[\frac{\mathrm{W}}{\gamma_{r}}\right]^{1 / 3}=3 \times 1,15\left[\frac{4,152}{2,65}\right]^{1 / 3}=4,007 \mathrm{~m}
\end{aligned}
$$

Jadi lebar puncak seawall adalah $4 \mathrm{~m}$.

\section{Penentuan Jumlah Batu Lapis Lindung}

Untuk menentukan jumlah batu lapis lindung menggunakan rumus berikut:

$$
N=A \times n \times K_{\Delta}\left[1-\frac{P}{100}\right] \times\left[\frac{W}{\gamma_{r}}\right]^{2 / 3}
$$

Dimana :

$\mathrm{N}=$ Jumlah butir batu satu satuan luas permukaan $\mathrm{A}$

$\mathrm{n} \quad=$ Jumlah Lapis batu dalam lapis pelindung

$$
\begin{array}{ll}
\mathrm{K}_{\Delta} & =\text { Koefisien Lapis Lindung }(1,15) \\
\mathrm{A} & =\text { Luas Permukaan }=10\left(\mathrm{~m}^{2}\right) \\
\mathrm{P} & =\text { Porositas rerata lapis pelindung } \\
& =37 \text { (Lampiran 7) } \\
\mathrm{W} & =\text { Berat butir lapis pelindung } \\
& =5,019 \text { (ton) } \\
\left(\gamma_{\mathrm{r}}\right) & =\text { Berat Jenis lapis lindung (Beton } \\
& =2,4)
\end{array}
$$

$$
N=10 \times 2 \times 1,15\left[1-\frac{37}{100}\right] \times\left[\frac{2,65}{4,152}\right]^{2 / 3}=11
$$

Jadi, jumlah butir batu lapis lindung tiap $10 \mathrm{~m}^{2}$ sebanyak 11 buah.

\section{Perhitungan Pelindung kaki (toe protection)}

Perhitungan berat batu lindung untuk bagian kaki bangunan dapat dihitung sebagai berikut :

Berat batu pelindung kaki :

$$
\begin{aligned}
\frac{\mathrm{W}}{10}=\frac{4,152}{10} & =0,4152 \text { ton } \\
& =415,2 \text { kilogram }
\end{aligned}
$$

Lebar pelindung kaki dapat dihitung dengan rumus:

$\mathrm{B}=2 \times \mathrm{H}$

Perhitungan lebar kaki bagian kepala:

$$
\begin{aligned}
\mathrm{B} & =2 \times 2,9 \\
& =5,8 \text { meter }
\end{aligned}
$$

Jadi, dari perhitungan diatas didapatkan berat batu pelindung bagian kaki sebesar 415,2 $\mathrm{kg}$ dan lebar pelindung kaki sebesar 5,8 meter.

\section{Kesimpulan}

1. Berdasarkan data BMKG dalam waktu 10 tahun 2010-2019, tinggi gelombang signifikan (Hs) terbesar adalah setinggi 2,90 meter, termasuk kedalam kategori gelombang tinggi, yaitu berkisar 2,50$4,0 \mathrm{~m}$ dan periode gelombang signifikan (Ts) terbesar adalah sebesar 6,90 detik. Sedangkan elevasi muka air rencana sebesar 2,20 meter dan elevasi puncak nya sebesar $5,31 \mathrm{~m}$.

2. Dimensi seawall yang diperoleh dari hasil perhitungan yaitu :

a. Lebar puncak pemecah seawall tersebut adalah 4 meter. Berat lapis pelindung luar $\mathrm{W}$ adalah sebesar 4,152 ton dan tebal lapis lindungnya $t$ adalah sebesar 2,671 meter.

b. Berat lapis pelindung kedua sebesar 415,2 kg. tebal lapis 
lindung kedua adalah sebesar 1,239 meter.

c. Berat lapis core layer adalah sebesar $21 \mathrm{~kg}$.

d. Berat butir pelindung kaki seawall sebesar 415,2 kg.

e. Jumlah lapis pelindung tiap $10 \mathrm{~m}^{2}$ sebanyak 11 buah.

\section{DAFTAR PUSTAKA}

Asnawi, 2012.Perencanaan Bangunan Pengaman Pantai di Bulu Tuban.Skripsi. Program Studi Teknik Sipil. Surabaya: ITS.

Duani, K, P., 2016. Analisis Struktur Bangunan Pengaman Pantai Air PadangKecamatan Lais Bengkulu Utara.Skripsi. Program Studi Teknik Sipil.Bengkulu: Universitas Bengkulu.

Istijono, B., 2014. Analisis Penilaian Kinerja Bangunan Pengaman Pantai Terhadap Abrasi di Kota Padang.Skripsi. Program Studi Teknik Sipil. Padang: Universitas Andalas..

Triatmodjo, B., 1999. Teknik Pantai. Yogyakarta: Beta Offset.

Triatmodjo, B., 2012. Perencanaan Bangunan Pantai. Yogyakarta: Beta Offset.

Widhianto, S. L., Kharisma, D., Suharyanto, S., dan Hardiyati, S., 2015.Kajian Struktur Pengaman Pantai Sigandu. Batang.Jurnal karya teknik sipil, 3(4), 1207-1221 